\title{
Ficus hirta fruits extract incorporated into an alginate-based edible coating for Nanfeng mandarin preservation
}

Chuying Chen ${ }^{\mathrm{a}}, \quad$ Xuan Penga,$\quad$ Rong Zeng ${ }^{\mathrm{b}}, \quad$ Ming Chen ${ }^{\mathrm{a}}, \quad$ Chunpeng Wan ${ }^{\mathrm{a}}$, Jinyin Chen ${ }^{\mathrm{a}}$

a Jiangxi Key Laboratory for Postharvest Technology and Nondestructive Testing of Fruits \& Vegetables, Jiangxi Agricultural University, Nanchang 330045, PR China

${ }^{\mathrm{b}}$ Department of Food Science, Foshan University, Foshan 528000, PR China

Corresponding author: Jinyin Chen, College of Agriculture, Jiangxi Agricultural University,

Nanchang City 330045, Jiangxi Province, PR China. Tel.: +86-791-83813492; Fax:

$+86-791-83813492$.

E-mail address: jinyinchen@126.com or ccy0728@126.com

Running title: Nanfeng mandarin Preservation 


\begin{abstract}
:
An edible coating based on $1.5 \%$ sodium alginate (SA), $0.7 \%$ citric acid and $1.0 \%$ sucrose ester with and without Ficus hirta $(\mathrm{FH})$ fruit extract was applied to Nanfeng mandarins to preserve their postharvest quality. Changes in decay rate, weight loss, quality parameters, respiration rate, and enzymatic activities of the coated and control samples were assessed at 10-day intervals for a 100-day storage period at $6{ }^{\circ} \mathrm{C}$. The decay rate, weight loss, respiration rate and maleicdialdehyde (MDA) content were much lower in the FH-SA coated samples than in the control group. During the middle and later periods of storage, Nanfeng mandarin treated with FH-SA coating maintained good fruit quality. The FH-SA coating treatment enhanced the activities of antioxidant and defense-related enzymes such as superoxyde dismutase (SOD), catalase (CAT), peroxidase (POD), chitinase (CHI), $\beta$-1,3-glucanase (GLU), and phenylalanine ammonialyase (PAL), and stimulated the accumulation of phenolic compounds. Our study suggests that FH-SA coating has the potential to enhance the long term quality and storage of Nanfeng mandarin.
\end{abstract}

Keywords: coating; sodium alginate; Ficus hirta extract; postharvest quality; Nanfeng mandarin. 


\section{Introduction}

Nanfeng mandarin (Citrus reticulata Blanco cv. 97-2) fruits, which enjoy great popularity in China and many other countries due to its good taste and abundance of nutrients, has been cultivated for over 1300 years (Zeng et al., 2012a). However, there are serious problems restricting the development of citrus production. Postharvest losses, usually the result of decay caused by a variety of plant pathogenic fungi, and a lacked of scientific management are issues which need to be addressed and solved, with postharvest decay being the biggest of these two hurdles.

Edible coatings, similar to modified atmosphere packaging, have been shown to protect horticultural products from mechanical damage, transpiration, respiration, and pathogen infection by providing a beneficial semi-permeable film around the fruit (Falguera et al., 2011). Edible coatings based on polysaccharides, for example mixtures of starch, chitosan, locust bean gum (Rojas-Argudo et al., 2009), carrageenan and carboxymethyl cellulose (Togrul and Arslan, 2004), aloe vera (Adetunji et al., 2012), galactomannans (Cerqueira et al., 2011), and hydroxypropyl methylcellulose (Valencia-Chamorro et al., 2009), have been investigated as a means of improving the storability of citrus fruits. Among them, sodium alginate, a polysaccharide derived from marine brown algae, has played a dominant role due to its unique colloidal properties and its ability to form strong gels in aqueous solutions. This has gained significant attention and sodium alginate has been evaluated for numerous applications in the food, medicine, cosmetics, and printing markets (Tripathy and Singh, 2001; Yao et al., 2010). The addition of antifungal components to alginate-based films can improve their antifungal activity and prolong the storage life of fruits and vegetables. 
Currently, we have screened 113 herb extracts for antifungal activity against Penicillium italicum and Penicillium digitatum, and demonstrated that the Ficus hirta extract was able to significantly inhibit both Penicillium molds in vitro. The Ficus hirta $(\mathrm{FH})$ is a deciduous plant known in China by the name of "Wú Zhǐ Máo Táo. It is widely distributed in southern China and used as a traditional plant source of medicine and food by the Hakka people. The fruits of FH are used in Chinese folk medicine to treat constipation, postpartum hypogalactia, hepatitis, and tumors (Ya et al., 2010; Zeng et al., 2012c). Not surprisingly, sodium alginate coatings enriched in FH extract provide enhanced antifungal activity and it is likely that research will broaden the practical applicability of this botanical fungicide. However, to the best of our knowledge, the use of sodium alginate, either individually or in combination with FH extract, has not been examine in fresh citrus fruits. Thus, the objective of this study was to evaluate the effect of FH extract incorporated into alginate-based edible coatings on cold-stored Nanfeng mandarin.

\section{Materials and methods}

\subsection{Plant materials}

The Nanfeng mandarin (Citrus reticulata Blanco cv. 97-2) fruits used throughout this study were harvested from a local orchard located in Nanfeng city (Jiangxi Province, China) in early November, 2014. The fruits were picked on the basis of their healthy, uniform color and their viability as commercially mature fruits without bruises or disease. The fruits were then placed in plastic boxes and immediately carried back to Jiangxi Key Laboratory for Postharvest Technology and Nondestructive Testing of Fruits \& Vegetables within $3 \mathrm{~h}$. 
The Ficus hirta fruits (origin: Guangdong province, China) were purchased from Huafeng herbs store in Zhangshu (Jiangxi Province, China) and powdered in a grinder (less than 20 mesh) after drying at $45^{\circ} \mathrm{C}$.

\subsection{Coating and treatments}

\subsubsection{Preparation of FH extract}

A $100 \mathrm{~g}$ powder sample was suspended in $1 \mathrm{~L} 95 \%$ ethanol (v/v) at $45{ }^{\circ} \mathrm{C}$ with ultrasonic assisted extraction $(40 \mathrm{kHz}$ ) for $60 \mathrm{~min}$, followed by three successive extractions. The combined supernatants were filtered and concentrated by vacuum distillation at $45{ }^{\circ} \mathrm{C}$ using a Buchi rotary evaporator. The remaining solution of $1 \mathrm{~g} / \mathrm{mL}$ (raw herb/solvent: w/v) was referred to as the crude extract and stored at $4{ }^{\circ} \mathrm{C}$ for further use.

\subsubsection{Fungal decay index caused by P. italicum}

The inoculation method was used to evaluate the in vivo effectiveness of FH extracts in controlling postharvest fungal decay in citrus fruits. The fungal pathogen, $P$. italicum, was isolated from an infected citrus fruit showing the typical blue mold. The selected fruits of the same size and color, without any injuries and infections, were dipped in a $1 \%$ sodium hypochlorite solution for $2 \mathrm{~min}$, rinsed with sterile water, and air-dried. The fruits were punctured at the equatorial region with a sterile puncher, generating a uniform wound ( $4 \mathrm{~mm}$ wide, $2 \mathrm{~mm}$ deep), and then divided randomly into five groups and placed in containers ( $35 \mathrm{~cm} \times 26 \mathrm{~cm}$ white plastic boxes). 15 $\mu \mathrm{L}$ of $\mathrm{FH}$ extract at $12.5,25,50,100 \mathrm{mg} \cdot \mathrm{mL}^{-1}$, along with sterile distilled water as a control, was pipetted into the wounds. After $30 \mathrm{~min}, 15 \mu \mathrm{L}$ of spore suspension of P. italicum $\left(5 \times 10^{4}\right.$ spore $\cdot \mathrm{mL}^{-1}$ ) was inoculated into each wound. The diameters of the lesions in the decayed fruits 
were recorded after 7 days of incubation at $25{ }^{\circ} \mathrm{C}$ using the formula: inhibition $(\%)=($ lesion area of control - lesion area of treatment)/ lesion area of control $\times 100$. The fruits were used per treatment and each treatment was carried out with three replicates.

\subsubsection{Preparation of films with incorporated FH extract}

Sodium alginate (SA, Kangyuan Products \& Chemical Ltd., China) solution (1.5\%, w/v) was prepared by dissolving $1.5 \mathrm{~g}$ of SA powder in $100 \mathrm{~mL}$ of hot water $\left(45^{\circ} \mathrm{C}\right)$, which was continuously shaken for $2 \mathrm{~h}$. After cooling to room temperature, citric acid at $0.7 \%(\mathrm{~m} / \mathrm{v})$ and sucrose ester at $1.0 \%(\mathrm{~m} / \mathrm{v})$ were added as an antioxidant and a surfactant, respectively. All the film forming aids were food grade. $5 \mathrm{~mL}$ crude FH extract was added into the coating, with continuous shaking for $20 \mathrm{~min}$.

\subsubsection{Coating application}

The selected fruits were washed with tap water, air-dried at room temperature $\left(25 \pm 1{ }^{\circ} \mathrm{C}\right)$, and then coated by dipping them in a SA coating and/or FH extract for 2 min (FH-SA and 1.5\% SA coating). The control group was treated without coating. After drying, the coated as well as control fruits were pre-cooled $\left(10{ }^{\circ} \mathrm{C}, 12 \mathrm{~h}\right)$. Finally, all fruits were stored at $6 \pm 0.5{ }^{\circ} \mathrm{C}$ and approximately $90 \%$ RH.

\subsection{Physicochemical quality parameters}

\subsubsection{Decay rate and weight loss}

A total of 600 fruits were divided randomly into three groups to measure decay rate and weight loss. 180 fruits were used per treatment to measure decay rate, while the remaining 20 
fruits were used to measure weight loss. Decay rate was expressed as the percentage of fruits showing indication of fungal disease. Weight loss was measured every 10 days during storage and compared with initial weight.

\subsubsection{Total soluble solid, titratable acid, total sugar and ascorbic acid}

The total soluble solid (TSS) content of pulp juice was assayed by a RA-250 WE digital brix-meter (KYOTO, Tokyo, Japan) and expressed as ${ }^{\circ}$ Brix. Titratable acid (TA) in pulp juice was assayed based using the method of Serrano (Serrano et al., 2005) with some minor modifications. Briefly, $5.0 \mathrm{~g}$ of pulp juice was diluted with $50 \mathrm{~mL}$ of distilled water, titrated to a $\mathrm{pH} 8.1$ with 0.1 $\mathrm{M} \mathrm{NaOH}$, and expressed as a percentage of citric acid. The total sugar content was determined using the anthrone colorimetric method. For ascorbic acid (AsA) analysis, $5.0 \mathrm{~g}$ of juice was well homogenized with $20 \mathrm{~mL}$ of $2 \%\left(\mathrm{w} / \mathrm{v}\right.$ ) oxalic acid and centrifuged at $12,000 \times \mathrm{g}$ at $4{ }^{\circ} \mathrm{C}$ for $10 \mathrm{~min}$. The AsA content in the supernatant was titrated with a standard 2, 6-dichlorophenol indophenol and expressed as mg ascorbic acid per $100 \mathrm{~g}$ fresh fruit pulp. Each treatment contained three replicates with 10 fruits per replicate.

\subsubsection{Assay of total phenolics and flavonoids}

The total phenolic content (TPC) and total flavonoid content (TFC) was measured using the methods of Liu et al., (2007) with some modifications. $5.0 \mathrm{~g}$ of peel tissue was homogenized with $20 \mathrm{~mL}$ of ice-cold $1 \%(\mathrm{v} / \mathrm{v}) \mathrm{HCl}-\mathrm{methanol}$ and centrifuged at $12,000 \times \mathrm{g}$ at $4{ }^{\circ} \mathrm{C}$ for $15 \mathrm{~min}$. The supernatants were collected and used for assaying the TPC and TFC. The TPC and TFC were expressed as $\mathrm{OD}_{280} \mathrm{~g}^{-1} \mathrm{FW}$ and $\mathrm{OD}_{325} \mathrm{~g}^{-1} \mathrm{FW}$, respectively.

\subsubsection{Measurement of respiration rate and MDA content}


$\mathrm{CO}_{2}$ concentration was measured from 10 fruits from each treatment. The fruits were placed in an airtight plexi-glass jar, with a metal probe in the headspace, for $2 \mathrm{~h}$ at $25{ }^{\circ} \mathrm{C}$ prior to gas sampling. The $\mathrm{CO}_{2}$ concentration was recorded by a $\mathrm{GHX}-3051 \mathrm{H}$ infrared $\mathrm{CO}_{2}$ fruit and vegetable breathing apparatus (Jingmi Scientific LLC., Shanghai, China). Respiration rate was calculated by using the following equation:

$$
\text { Respiration rate }=\frac{\Delta \mathrm{CO}_{2}}{100} \cdot \mathrm{V}_{\text {headspace }} \cdot \frac{1000}{\mathrm{~m}} \cdot \frac{60}{\mathrm{t}}
$$

Where $m$ is the mass of Nanfeng mandarin $(\mathrm{g}), \mathrm{V}_{\text {headspace }}$ is the empty volume of the jar $(\mathrm{mL})$, $\Delta \mathrm{CO}_{2}$ is the difference between the initial and final concentration of $\mathrm{CO}_{2}$ and $t$ is recording time (min).

Peel tissue $(2.0 \mathrm{~g})$ from 10 fruits in each treatment was homogenized in $10 \mathrm{~mL}$ of $50 \mathrm{mM}$ phosphate (PBS) buffer at $\mathrm{pH} 7.8$ and centrifuged at 12,000 $\times \mathrm{g}$ for 20 min. MDA content was measured using the method of Hodges et al, (1999) with some slight modifications. The supernatant was collected and $2.0 \mathrm{~mL}$ was mixed with $4.0 \mathrm{~mL}$ of $0.5 \%$ thiobarbituric acid. The mixture was heated to $100{ }^{\circ} \mathrm{C}$ for $30 \mathrm{~min}$, quickly cooled, and then centrifuged at $6000 \times \mathrm{g}$ for 10 min. The supernatant was collected and used to measure absorbance at 450, 532 and $600 \mathrm{~nm}$. The MDA concentration (mmol/g FW) was calculated using the formula:

$$
\left[6.452 \times\left(\mathrm{A}_{532}-\mathrm{A}_{600}\right)-0.559 \times \mathrm{A}_{450}\right]
$$

\subsubsection{Assay of enzymatic activities}

Peel tissue $(2.0 \mathrm{~g})$ from 10 fruits from each treatment condition were homogenized in $25 \mathrm{~mL}$ of ice-cold $50 \mathrm{mM}$ PBS buffer at $\mathrm{pH} 7.8$, containing $0.5 \mathrm{mM}$ ascorbic acid, $1 \mathrm{mM}$ EDTA and $2 \%$ polyvinyl pyrrolidone $(\mathrm{PVP}, \mathrm{m} / \mathrm{V})$, and centrifuged at $12000 \times \mathrm{g}$ at $4{ }^{\circ} \mathrm{C}$ for $30 \mathrm{~min}$. The 
supernatants were used for assaying the enzymatic activity of SOD, CAT, and POD.

Total SOD activity was determined by using a "SOD Detection Kit" following the manufacturer's instruction (NJBI, Nanjing, China). The absorbance was monitored at $550 \mathrm{~nm}$ (Shimadzu UV-1800, Japan). One unit of SOD gives a 50\% reduction of xanthine. CAT activity was assayed by monitoring the disappearance of $\mathrm{H}_{2} \mathrm{O}_{2}$ using the method of Greenwald (1987) with slight modifications. One unit of CAT activity resulted in a 0.01 absorbance change per minute at $240 \mathrm{~nm}$. POD activity was based on the assay for guaiacol oxidation at $470 \mathrm{~nm}$ in the presence of $\mathrm{H}_{2} \mathrm{O}_{2}$. One unit of POD activity was defined as the amount of enzyme that resulted in a 0.01 absorbance increase per min.

For the chitinase (CHI) and $\beta$-1,3-glucanase (GLU) activity assays, peel tissue (5.0 g) from 10 fruits was mixed with $25 \mathrm{~mL}$ of ice-cold $100 \mathrm{mM}$ sodium acetate buffer at $\mathrm{pH} 5.2$, containing 1\% PVP, $5 \mathrm{mM} \beta$-mercaptoethanol and $1 \mathrm{mM}$ EDTA, and then centrifuged at $12000 \times \mathrm{g}$ for $30 \mathrm{~min}$ at $4{ }^{\circ} \mathrm{C}$. Then the supernatant was then desalted by dialysis overnight at $4{ }^{\circ} \mathrm{C}$ and used for the enzymatic assay. Determination of CHI and GLU activity was performed using the method described by Zeng et al. (2012b). One unit of CHI activity was defined as the enzyme activity that catalyzed the formation of $1 \mathrm{nmol}$ of N-acetyl-d-glucosamine per hour. For GLU, one unit of enzyme activity was defined as the amount of enzyme that produced a reducing sugar equivalent to $1 \mathrm{nmol}$ glucose equivalents released from laminarin per hour.

For the phenylalanine ammonia-lyase (PAL) activity assay, peel tissue (2.0 g) was homogenized with $6.0 \mathrm{~mL}$ of ice-cold $50 \mathrm{mM}$ Tris- $\mathrm{HCl}$ buffer at $\mathrm{pH} 8.8$, containing $15 \mathrm{mM}$ $\beta$-mercaptoethanol, $5 \mathrm{mM}$ EDTA, $5 \mathrm{mM}$ ascorbic acid, $1 \mathrm{mM}$ phenylmethanesulfonyl fluoride 
(PMSF) and 4\% PVP, and then centrifuged at $12000 \times \mathrm{g}$ for 20 min at $4{ }^{\circ} \mathrm{C}$. The supernatant was then collected and used for the enzymatic assay. PAL activity was determined using the method described by Ballester et al. (2006). The enzyme activity was expressed as units (U) per gram of FW. The amount of trans-cinnamic acid produced was measured spectrophotometrically at $290 \mathrm{~nm}$ and one unit of PAL activity was expressed as $1 \mathrm{ng}$ of trans-cinnamic acid released per hour.

\subsection{Statistical analysis}

A completely randomized design (CRD) was used with three replicates, with each replicate consisting of 10 fruits for each treatment. The experimental data were expressed as means \pm standard deviation (S.D.) and subjected to statistical analysis using the SPSS version 17.0 (SPSS Inc., Chicago, IL, USA). The data were analyzed by one-way analysis of variance (ANOVA). Duncan's multiple range test was used for significant differences at levels of $P<0.05$ and $P<0.01$.

\section{Results}

\subsection{Efficacy of FH extract in controlling blue mold decay caused by P. italicum}

The efficacy control of postharvest blue mold in Nanfeng mandarin fruit inoculated with $P$. italicum was effectively reduced by treatment with $\mathrm{FH}$ extract at different concentrations. As shown in Fig.1A, the diameters of the lesions in the FH extract treated fruits were significantly lower than that in control fruit over the incubation at $25^{\circ} \mathrm{C}$ for 7 days. Meanwhile, after 7 days of the incubation, the inhibition percentage of blue mold in Nanfeng mandarin treated with $12.5,25$, 50, $100 \mathrm{mg} \mathrm{mL}^{-1} \mathrm{FH}$ extract was $26.9 \%, 37.3 \%, 50.4 \%$ and $62.8 \%(P<0.05$ and $P<0.01)$ smaller than that in the control group, respectively. In addition, the $\mathrm{R}^{2}$ value of inhibition percentage of blue mold was noted to be 0.9427 with the logarithmic equations of $y=25.166 \ln (x)+24.362$, 
which was close to 1.0 , indicating that there is a good relationship between inhibition percentage and concentrations of the FH extract (Fig.1B).

\subsection{Changes in decay rate and weight loss of Nanfeng mandarin}

Fig.2 shows the changes in decay rate and weight loss both for the uncoated group and those with a SA and/or FH extract coating throughout the cold storage period. As shown in Fig.2A, FH-SA and $1.5 \%$ SA coatings delayed the appearance of fungal infection in comparison to the uncoated group, which started to decay after 30 days of storage. Many of the control fruits (16.6\%) were rotten at the end of the storage, while the percentage of infected fruits from the coated treatments was below $10 \%$. The decay rate of fruits treated by FH-SA and 1.5\% SA coatings were significantly lower than that of the control group at the level of $P<0.01$ (7.8\% and $9.3 \%$, respectively).

Water loss or transpiration is another factor that affects the preservation of horticultural produces. Fig.2B shows the extent of the weight loss during storage for both coated treatments and the control group. For the full duration of the experiment the percentage of weight loss in the uncoated control group was higher than in the coated treatments. Our statistical analysis revealed that the weight loss in the control group was significantly different from coated fruits $(P<0.01)$. After 60 days of storage, the weight loss in the control group increased to almost three and two times that of the fruits treated by the FH-SA and $1.5 \%$ SA coatings, respectively,

\subsection{Changes in fruit quality parameters of Nanfeng mandarin}

The changes in the content of TSS, TA, total sugar and AsA are shown in Fig.3. As illustrated in Fig.3A and C, the content of TSS and total sugar increased continuously during the early stages of storage and decreased slightly in the later storage period. The content of TSS and 
total sugar in the control group reached its highest level at 30 days, while the content of TSS and total sugar in the coated treatments pesked at 50 days and 40 days, respectively. There is no significant difference between the three peaks of TSS content. During the last 50 days of storage, the TSS and total sugar content of the FH-SA coated samples were significantly higher $(P<0.05)$ than in the $1.5 \%$ SA coated fruit and the control group.

The TA content of all samples fell greatly after 100 days of storage (Fig.3B) and the value was significantly higher $(\mathrm{P}<0.05)$ in the FH-SA coated treat fruit compared to the $1.5 \%$ SA coated fruit and the control group. During the storage, the control group showed a greater TA loss, with an average rate of $0.105 \%$ per 10 days, while the rate of TA loss in the FH-SA and $1.5 \%$ SA coated fruits was $0.082 \%$ and $0.094 \%$ per 10 days, respectively.

The AsA content of both the coated and control groups reached their maximum after 20 days of storage and declined later in the storage period (Fig.3D). The highest level of AsA was observed in the FH-SA coated fruit, closely followed by fruit treated with the $1.5 \%$ SA coating. During the last 60 days of storage, the AsA content in FH-SA coated fruit was nearly significantly higher $(P<0.05)$ than that in the $1.5 \%$ SA coated fruit and the control group.

Fig.4 demonstrated that FH-SA coating notably $(P<0.05)$ increased the level of total phenolic and total flavonoid compounds. The TPC and TFC in the control group initially increased steadily and then peaked at 70 days and 80 days of storage, respectively. In addition, the TPC and TFC in the FH-SA treated fruit initially increased and then reached a peak value at the same time.

\subsection{Changes in respiration rate and MDA content of Nanfeng mandarin}

As illustrated in Fig.5A, the respiration rate decreased initially in the first 60 and 70 days of 
storage in all the coated and uncoated fruit, after which there was a sharp increase in respiration rate. The respiration rate in the control group reached $8.04 \pm 0.03 \mathrm{mg} \mathrm{CO}_{2} \mathrm{~kg}^{-1} \mathrm{~h}^{-1}$ at 60 days, while the coating treatments reached lower levels $\left(5.06 \pm 0.22\right.$ and $5.68 \pm 0.31 \mathrm{mg} \mathrm{CO}_{2} \mathrm{~kg}^{-1} \mathrm{~h}^{-1}$ respectively) 10 days later than the control group. During the middle and late of storage period, the respiration rate of the FH-SA coated fruit was significantly lower $(P<0.05)$ than that of the $1.5 \%$ SA coated and the control group.

As shown in Fig.5B, MDA content increased constantly during storage and a significant difference was seen between the coating treatments and the control group. At the end of storage, the MDA content of the control reached a maximum $\left(2.55 \mathrm{mmol} \cdot \mathrm{g}^{-1}\right)$ that was $22.4 \%$ higher than that of the FH-SA coated fruit and $14.1 \%$ higher than the $1.5 \%$ SA coated fruit, respectively.

\subsection{Changes in antioxidant and defense-related enzymes}

During cold storage SOD and CAT activity increased and then later decreased. SOD and CAT activity in the control group increased to a peak at 40 days after treatment, and then dropped quickly the following day (Fig.6A and B). The coated treatments peaked at 60 days, 20 days after the control group, with the peak for the FH-SA coated treatment being significantly higher $(P<0.05)$ than that of the control group. During the last 50 days of storage, the SOD and CAT activity in the FH-SA coated samples was significantly higher $(P<0.05)$ than in the $1.5 \% \mathrm{SA}$ coated treatment and the control group. POD activity in all samples increased rapidly and reached peaks at 30 days after storage, followed by a decline during the subsequent storage period. The peaks in the coated treatments were significantly higher $(P<0.05)$ than that of the control group

(Fig.6C). During the later storage period, POD activity in the FH-SA coated fruit was significantly higher $(P<0.05)$ than in the $1.5 \%$ SA coated fruit and the control group. 
The changes in the activity of defense-related enzymes, such as CHI, GLU and PAL are shown in Fig.6. The CHI activity decreased slightly during the first 20 days and then increased noticeably at the end of the storage period (Fig.6D). The FH-SA and 1.5\% SA coated treatment had relatively high CHI activity, approximately 1.34 times and 1.22 times higher than the control group. The change in GLU activity is shown in Fig.6E, GLU activity in all the samples fell greatly after 100 days of storage, with values being significantly higher $(P<0.05)$ in the FH-SA coated treatment compared to the $1.5 \%$ SA coated treatment and control samples. The PAL activity in the control group increased to a peak at 30 days, followed by a decrease during the remainder of the storage period, while the FH-SA and 1.5\% SA coated fruit reached peaks at 60 days, 30 days later than the control group. During storage, PAL activity in the FH-SA coated treatment was mainly significantly higher $(P<0.05)$ than in the $1.5 \%$ SA coated treatment (Fig.6F).

\section{Discussion}

Attempts to exploit natural preservatives have been drawing much attention as alternatives to synthetic fungicides as means of controlling postharvest diseases in citrus fruit (Shoresh et al., 2010). Numerous studies have documented the in vitro efficacy of plant extracts or essential oils against common postharvest diseases in citrus fruit (Plaza et al., 2004; Tripathi et al., 2004; Yahyazadeh et al., 2008). To function as a potential natural fungicide, high inhibition of diseases, low additive dose and positive effect on fruit quality are necessary. Our previous work has already verified that FH extract is effective in controlling the citrus fruit blue mold caused by $P$. italicum. The incorporation of FH extract into a $1.5 \%$ SA coating also has a positive impact on postharvest losses. The results of this research show that the FH-SA coating treatment can significantly reduce fruit decay and weight loss in the comparison to a $1.5 \%$ SA coating alone and the control group. 
These results are in accordance with previous reports that the application of sodium alginate coatings combined with some antifungal active ingredients can reduce diseases and weight loss in other fruits, such as strawberries, plums, peaches and grapes (Aloui et al., 2014; Fan et al., 2009; Ma et al., 2013; Maftoonazad et al., 2008; Valero et al., 2013). Therefore, the addition of FH extract to a $1.5 \%$ SA coating could be a promising approach in helping to reduce postharvest losses in Nanfeng mandarin.

Fruit quality parameters, including total soluble solid, titratable acid, total sugar, and ascorbic acid, reflect the storage properties of fruit. Fruits treated with FH-SA were found to have higher levels of TSS, TA, total sugar, and AsA. Our finding is supported by the results of Zeng et al. (2013) who reported that navel orange treated with a carboxymethyl cellulose (CMC) coating enriched with Impatiens balsamina L. stems extract displayed increased SSC, TA, AsA, and total sugar. In addition, similar results have also been reported by Castillo et al. (2014) who investigated lemons treated with commercial wax enriched in essential oils of thymol and carvacrol. Retention of higher levels of TSS, TA, total sugar, AsA, and total phenolics is due to the fact the coatings provided a beneficial semi-permeable film around the fruit, modifying the internal atmosphere by elevating $\mathrm{CO}_{2}$ and/or reducing $\mathrm{O}_{2}$ and delaying the degradation rate of nutrients in Nanfeng mandarin (Lin and Zhao, 2007).

Respiration rate is an important indicator of metabolic activity and provides an initial indication of the possible shelf life of horticultural products (Win et al., 2006). The results obtained in this study show that the application of FH-SA coating delayed and decrease the respiration rate of Nanfeng mandarin. These results are consistent with those of Azarakhsh et al. (2014), who showed that fresh-cut pineapple treated with lemongrass incorporated into an edible 
alginate-based coating had reduced carbon dioxide production and oxygen consumption, indicating delayed ripening and senescence compared to the control.

MDA is the final product of lipid peroxidation and its content has been used as a direct index of cell oxidative damage (Xu et al., 2009). We found that the MDA content of FH-SA coated fruits was lower compared to the $1.5 \%$ SA coated fruits and the control group, indicating that the FH-SA coating may have some significant positive effects on oxidative damage. Yage et al. (2011) also reported similar results for sweet pepper treated with a chitosan coating enriched with cinnamon oil.

SOD, CAT and POD, reactive oxygen species (ROS)-metabolizing enzymes have been confirmed to play crucial roles in scavenging free radicals (Ballester et al., 2006; Mittler, 2002). CHI and GLU, known as pathogenesis-related proteins, have been confirmed as playing a vitally important role in the defense against fungal disease in plants (Stintzi et al., 1993). PAL is the key enzyme of the phenylpropanoid metabolism, which is involved in enhancing disease resistance processes (Anderson et al., 1998; Stadnik and Buchenauer, 2000). In this study, we found that antioxidant enzymes, such as SOD, CAT and POD, and defense-related enzymes, such as CHI, GLU and PAL in the FH-SA coated fruits showed higher activity than those of control group or the $1.5 \%$ SA coated fruits. Similar results have also found in citrus fruits and other fruits in previous studies (Ma et al., 2013; Waewthongrak et al., 2015; Wang and Gao, 2013). These facts, together with our own work, suggest that the SA coating containing FH extract could induce the activity of some antioxidant enzymes and defense-related enzymes, thereby promoting disease resistance and delayed senescence. In addition, in our experiment the FH-SA coated fruit showed significantly higher activity in antioxidant and defense-related enzymes compared to $1.5 \%$ SA coating alone. 
The reason for this is probably that the FH extract added to the $1.5 \%$ SA coating induces the activity of these enzymes, which play important roles in disease resistance in Nanfeng mandarin. Our results are in agreement with those of Gao et al. (2013), who found that a chitosan-glucose complex coating showed higher activity of POD and SOD in table grapes when compared to chitosan and glucose coating alone.

The FH-SA coating has become a natural and safe alternative treatment for enhancing the storage of Nanfeng mandarin. After storage at $6{ }^{\circ} \mathrm{C}$ for 100 days, samples treated with the FH-SA coating showed a lower percentage of fruit decay and weight loss and significantly inhibited respiration. The positive effects of the FH-SA coating on postharvest lifespan and quality have been confirmed by our findings. In addition, the FH-SA coating treatment effectively enhanced SOD, CAT, POD, CHI, GLU, and PAL activities and stimulated the synthesis of phenolic compounds. Therefore, our results indicate that FH extract incorporated into a sodium alginate-based edible coating has the potential to prolong the postharvest life and maintain the fruit quality of Nanfeng mandarin during storage.

\section{ACKNOWLDGEMENTS}

This research was supported by National Science Foundation of China (NO. 31160343), the 12th Five-Year National Science \& Technology of Supporting Programs (NO. 2012BAD38B03-2) and Ministry of Agricultural Science \& Technology Achievements transformation fund of China (NO.2011GB2C50017). 


\section{References}

Adetunji, C., Fawole, A., Oloke, J., Adetunji, J., Makanjoula, O., 2012. Effect of edible coatings from Aloe vera gel on Citrus sinensis during ambient storage. Journal of Agricultural Research \& Development.

Aloui, H., Khwaldia, K., Sanchez-Gonzalez, L., Muneret, L., Jeandel, C., Hamdi, M., Desobry, S., 2014. Alginate coatings containing grapefruit essential oil or grapefruit seed extract for grapes preservation. International Journal of Food Science and Technology 49, 952-959.

Anderson, M.D., Chen, Z., Klessig, D.F., 1998. Possible involvement of lipid peroxidation in salicylic acid-mediated induction of PR-1 gene expression. Phytochemistry 47, 555-566.

Azarakhsh, N., Osman, A., Ghazali, H.M., Tan, C.P., Mohd Adzahan, N., 2014. Lemongrass essential oil incorporated into alginate-based edible coating for shelf-life extension and quality retention of fresh-cut pineapple. Postharvest Biology and Technology 88, 1-7.

Ballester, A.R., Lafuente, M.T., González-Candelas, L., 2006. Spatial study of antioxidant enzymes, peroxidase and phenylalanine ammonia-lyase in the citrus fruit-Penicillium digitatum interaction. Postharvest Biology and Technology 39, 115-124.

Castillo, S., Pérez-Alfonso, C.O., Martínez-Romero, D., Guillén, F., Serrano, M., Valero, D., 2014. The essential oils thymol and carvacrol applied in the packing lines avoid lemon spoilage and maintain quality during storage. Food Control 35, 132-136.

Cerqueira, M.A., Bourbon, A.I., Pinheiro, A.C., Martins, J.T., Souza, B.W.S., Teixeira, J.A., Vicente, A.A., 2011. Galactomannans use in the development of edible films/coatings for food applications. Trends in Food Science \& Technology 22, 662-671.

Falguera, V., Quintero, J.P., Jiménez, A., Muñoz, J.A., Ibarz, A., 2011. Edible films and coatings: 
Structures, active functions and trends in their use. Trends in Food Science \& Technology 22, 292-303.

Fan, Y., Xu, Y., Wang, D., Zhang, L., Sun, J., Sun, L., Zhang, B., 2009. Effect of alginate coating combined with yeast antagonist on strawberry (Fragaria x ananassa) preservation quality. Postharvest Biology and Technology 53, 84-90.

Gao, P., Zhu, Z., Zhang, P., 2013. Effects of chitosan-glucose complex coating on postharvest quality and shelf life of table grapes. Carbohydrate Polymers 95, 371-378.

Greenwald, R.A., 1987. Handbook of methods for oxygen radical research. Free Radical Biology and Medicine 3, 161-163.

Hodges, D.M., DeLong, J.M., Forney, C.F., Prange, R.K., 1999. Improving the thiobarbituric acid-reactive-substances assay for estimating lipid peroxidation in plant tissues containing anthocyanin and other interfering compounds. Planta 207, 604-611.

Lin, D., Zhao, Y., 2007. Innovations in the development and application of edible coatings for fresh and minimally processed fruits and vegetables. Comprehensive Reviews in Food Science and Food Safety 6, 60-75.

Liu, J., Tian, S., Meng, X., Xu, Y., 2007. Effects of chitosan on control of postharvest diseases and physiological responses of tomato fruit. Postharvest Biology and Technology 44, 300-306.

Ma, Z., Yang, L., Yan, H., Kennedy, J.F., Meng, X., 2013. Chitosan and oligochitosan enhance the resistance of peach fruit to brown rot. Carbohydrate Polymers 94, 272-277.

Maftoonazad, N., Ramaswamy, H.S., Marcotte, M., 2008. Shelf-life extension of peaches through sodium alginate and methyl cellulose edible coatings. International Journal of Food Science and Technology 43, 951-957. 
Mittler, R., 2002. Oxidative stress, antioxidants and stress tolerance. Trends in Plant Science 7, 405-410

Plaza, P., Torres, R., Usall, J., Lamarca, N., Vinas, I., 2004. Evaluation of the potential of commercial post-harvest application of essential oils to control citrus decay. Journal of horticultural science \& biotechnology 79, 935-940.

Rojas-Argudo, C., del Río, M.A., Pérez-Gago, M.B., 2009. Development and optimization of locust bean gum (LBG)-based edible coatings for postharvest storage of 'Fortune'mandarins. Postharvest Biology and Technology 52, 227-234.

Serrano, M., Martínez-Romero, D., Castillo, S., Guillén, F., Valero, D., 2005. The use of natural antifungal compounds improves the beneficial effect of MAP in sweet cherry storage. Innovative Food Science \& Emerging Technologies 6, 115-123.

Shoresh, M., Harman, G.E., Mastouri, F., 2010. Induced systemic resistance and plant responses to fungal biocontrol agents. Annual review of phytopathology 48, 21-43.

Stadnik, M.J., Buchenauer, H., 2000. Inhibition of phenylalanine ammonia-lyase suppresses the resistance induced by benzothiadiazole in wheat to Blumeria graminis f. sp. tritici. Physiological and Molecular Plant Pathology 57, 25-34.

Stintzi, A., Heitz, T., Prasad, V., Wiedemann-Merdinoglu, S., Kauffmann, S., Geoffroy, P., Legrand, M., Fritig, B., 1993. Plant 'pathogenesis-related' proteins and their role in defense against pathogens. Biochimie 75, 687-706.

Togrul, H., Arslan, N., 2004. Carboxymethyl cellulose from sugar beet pulp cellulose as a hydrophilic polymer in coating of mandarin. Journal of Food Engineering 62, 271-279.

Tripathi, P., Dubey, N., Banerji, R., Chansouria, J., 2004. Evaluation of some essential oils as botanical 
fungitoxicants in management of post-harvest rotting of citrus fruits. World journal of Microbiology and Biotechnology 20, 317-321.

Tripathy, T., Singh, R.P., 2001. Characterization of polyacrylamide-grafted sodium alginate: A novel polymeric flocculant. Journal of Applied Polymer Science 81, 3296-3308.

Valencia-Chamorro, S.A., Pérez-Gago, M.B., del Río, M.Á., Palou, L., 2009. Effect of antifungal hydroxypropyl methylcellulose (HPMC)-lipid edible composite coatings on postharvest decay development and quality attributes of cold-stored 'Valencia' oranges. Postharvest Biology and Technology 54, 72-79.

Valero, D., Díaz-Mula, H.M., Zapata, P.J., Guillén, F., Martínez-Romero, D., Castillo, S., Serrano, M., 2013. Effects of alginate edible coating on preserving fruit quality in four plum cultivars during postharvest storage. Postharvest Biology and Technology 77, 1-6.

Waewthongrak, W., Pisuchpen, S., Leelasuphakul, W., 2015. Effect of Bacillus subtilis and chitosan applications on green mold (Penicilium digitatum Sacc.) decay in citrus fruit. Postharvest Biology and Technology 99, 44-49.

Wang, S.Y., Gao, H., 2013. Effect of chitosan-based edible coating on antioxidants, antioxidant enzyme system, and postharvest fruit quality of strawberries (Fragaria x aranassa Duch.). LWT - Food Science and Technology 52, 71-79.

Win, T.O., Srilaong, V., Heyes, J., Kyu, K.L., Kanlayanarat, S., 2006. Effects of different concentrations of 1-MCP on the yellowing of West Indian lime (Citrus aurantifolia, Swingle) fruit. Postharvest Biology and Technology 42, 23-30.

Xu, W., Peng, X., Luo, Y., Wang, J., Guo, X., Huang, K., 2009. Physiological and biochemical responses of grapefruit seed extract dip on 'Redglobe' grape. LWT - Food Science and Technology 
$42,471-476$.

Ya, J., Zhang, X.Q., Wang, Y., Zhang, Q.W., Chen, J.X., Ye, W.C., 2010. Two new phenolic compounds from the roots of Ficus hirta. Natural Product Research 24, 621-625.

Yage, X., Xihong, L., Qinglian, X., Juan, Y., Yaqing, L., Yao, T., 2011. Effects of chitosan coating enriched with cinnamon oil on qualitative properties of sweet pepper (Capsicum annuиm L.) Food Chemistry $124,1443-1450$.

Yahyazadeh, M., Omidbaigi, R., Zare, R., Taheri, H., 2008. Effect of some essential oils on mycelial growth of Penicillium digitatum Sacc. World Journal of Microbiology and Biotechnology 24, 1445-1450.

Yao, B., Ni, C., Xiong, C., Zhu, C., Huang, B., 2010. Hydrophobic modification of sodium alginate and its application in drug controlled release. Bioprocess \& Biosystems Engineering 33, 457-463.

Zeng, R., Zhang, A., Chen, J., 2012a. Effects of carboxymethyl cellulose coating enriched with bacteriostatic preparation on cold preservation of Nanfeng mandarin. Transactions of the Chinese Society of Agricultural Engineering volume 28, 281-287(287).

Zeng, R., Zhang, A., Chen, J., Fu, Y., 2012b. Postharvest quality and physiological responses of clove bud extract dip on 'Newhall' navel orange. Scientia Horticulturae 138, 253-258.

Zeng, R., Zhang, A., Chen, J., Fu, Y., 2013. Impact of carboxymethyl cellulose coating enriched with extract of Impatiens balsamina stems on preservation of 'Newhall' navel orange. Scientia Horticulturae 160, 44-48.

Zeng, Y., Liu, X., Lv, Z., Peng, Y., 2012c. Effects of Ficus hirta Vahl. (Wuzhimaotao) extracts on growth inhibition of HeLa cells. Experimental and Toxicologic Pathology 64, 743-749. 

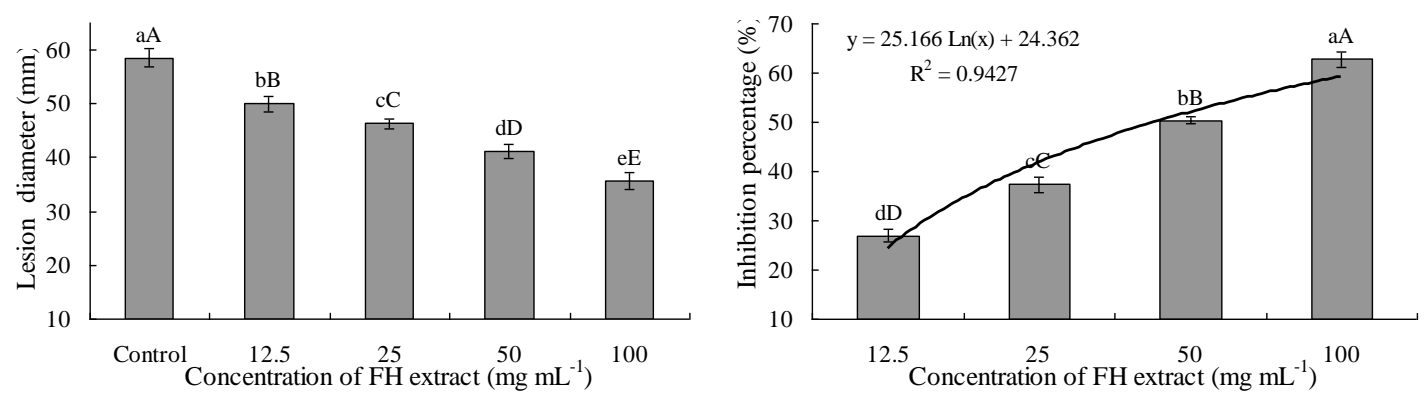

Fig.1. Changes in lesion diameter (A) and inhibition percentage (B) in Nanfeng mandarin treated with FH extract and inoculated with $P$. italicum during incubation at $25{ }^{\circ} \mathrm{C}$ for 7 days. Bars indicate the mean \pm standard deviation (S.D.) of three replicates and means labeled with different letters are significantly different at $\mathrm{p}<0.05$ and $\mathrm{p}<0.01$ according to Duncan's multiple range test.
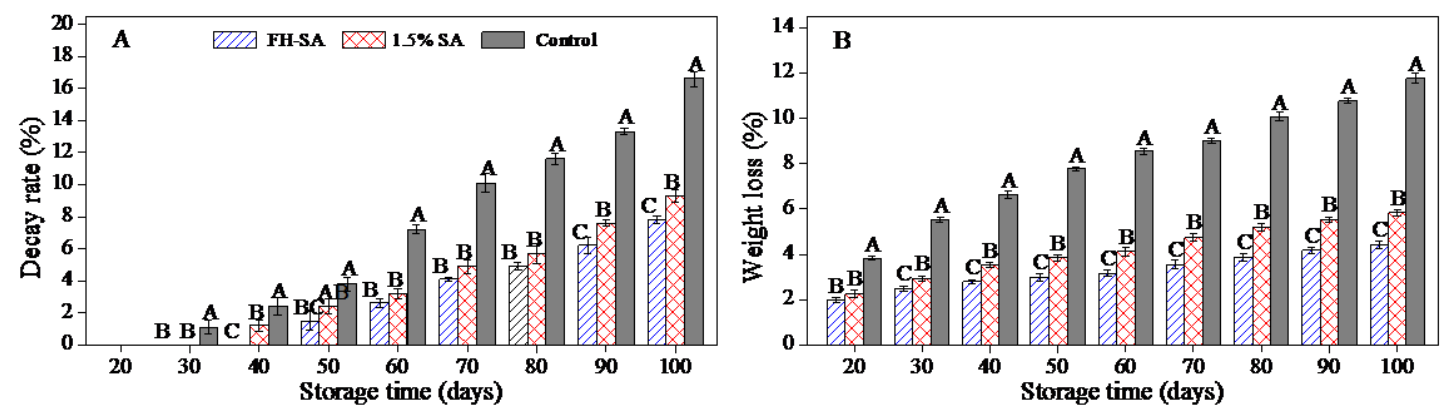

Fig.2. Changes in decay rate (A) and weight loss (B) of Nanfeng mandarin stored at $6{ }^{\circ} \mathrm{C}$ for 100 days. Bars indicate the mean \pm S.D. of three replicates and means labeled with different upper-case letters are significantly different at $\mathrm{p}<0.01$ according to Duncan's multiple range test.
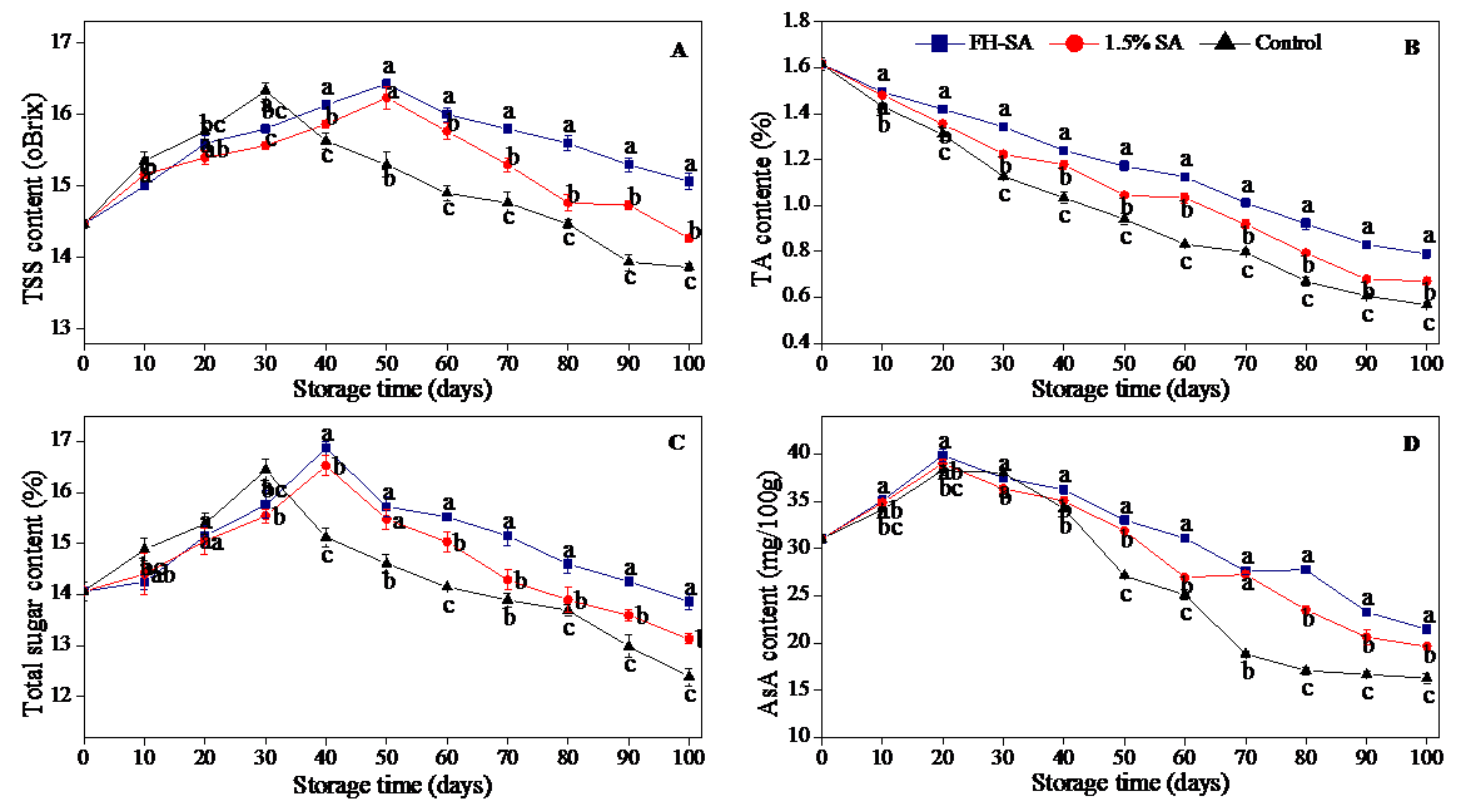

Fig.3. Changes in TSS (A), TA (B), total sugar (C) and AsA (D) content of Nanfeng mandarin stored at $6{ }^{\circ} \mathrm{C}$ for 100 days. Each value represents the mean \pm S.D. of three replicates and means labeled with different lower-case 
letters are significantly different at $\mathrm{p}<0.05$ according to Duncan's multiple range test.
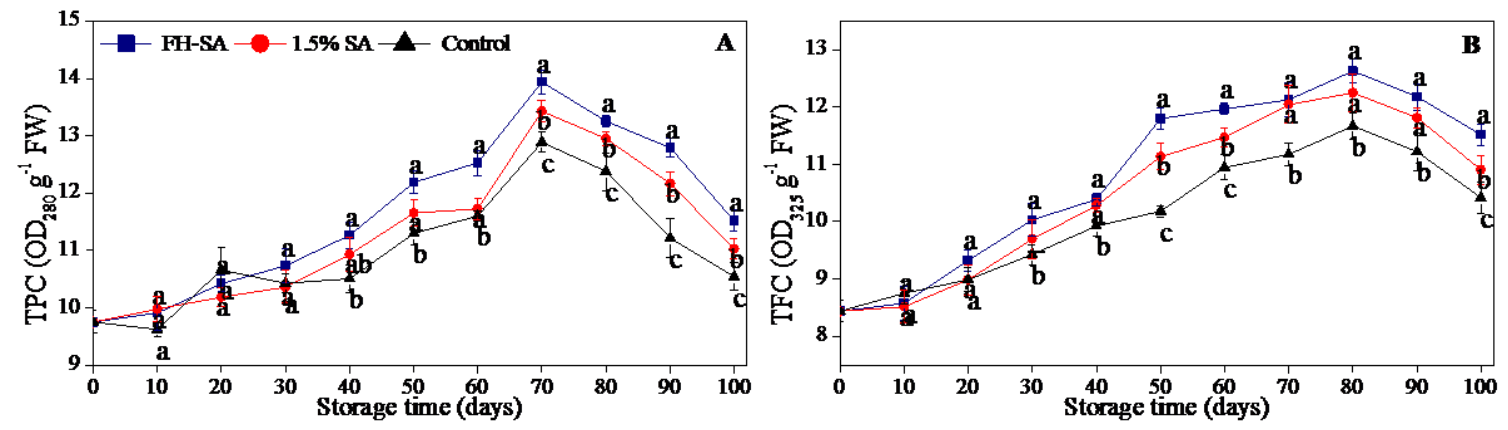

Fig.4. Changes in total phenolic (A) and total flavonoid content (B) of Nanfeng mandarin stored at $6{ }^{\circ} \mathrm{C}$ for 100 days. Each value represents the mean \pm S.D. of three replicates and means labeled with different lower-case letters are significantly different at $\mathrm{p}<0.05$ according to Duncan's multiple range test.

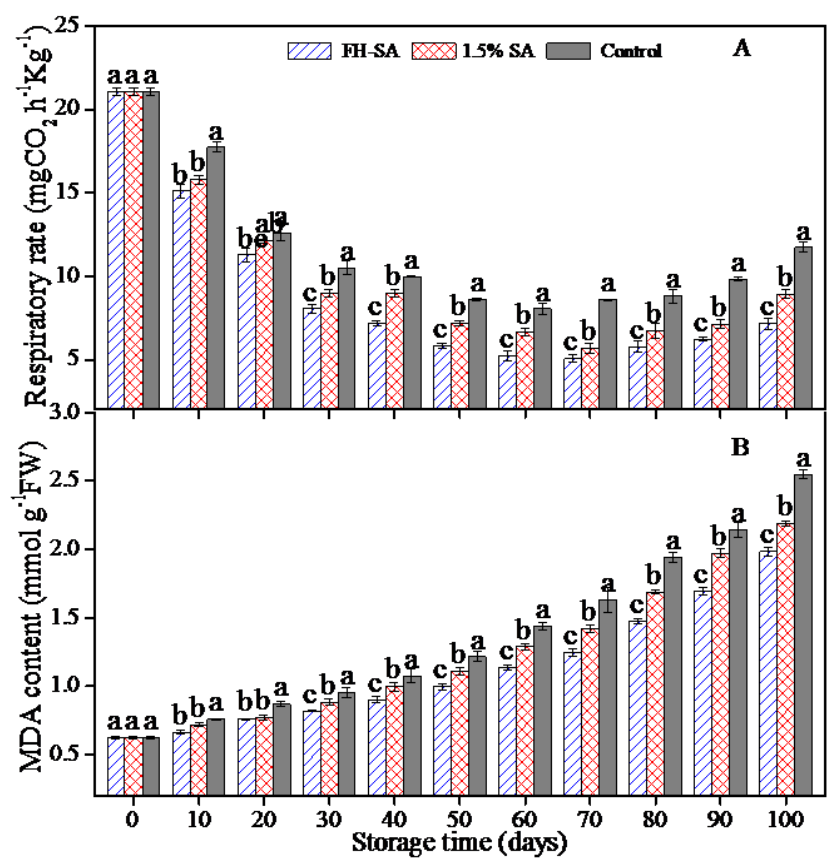

Fig.5. Changes in respiration rate (A) and MDA content (B) of Nanfeng mandarin stored at $6{ }^{\circ} \mathrm{C}$ for 100 days. Bars indicate the mean \pm S.D. of three replicates and means labeled with different lower-case letters are significantly different at $\mathrm{p}<0.05$ according to Duncan's multiple range test. 

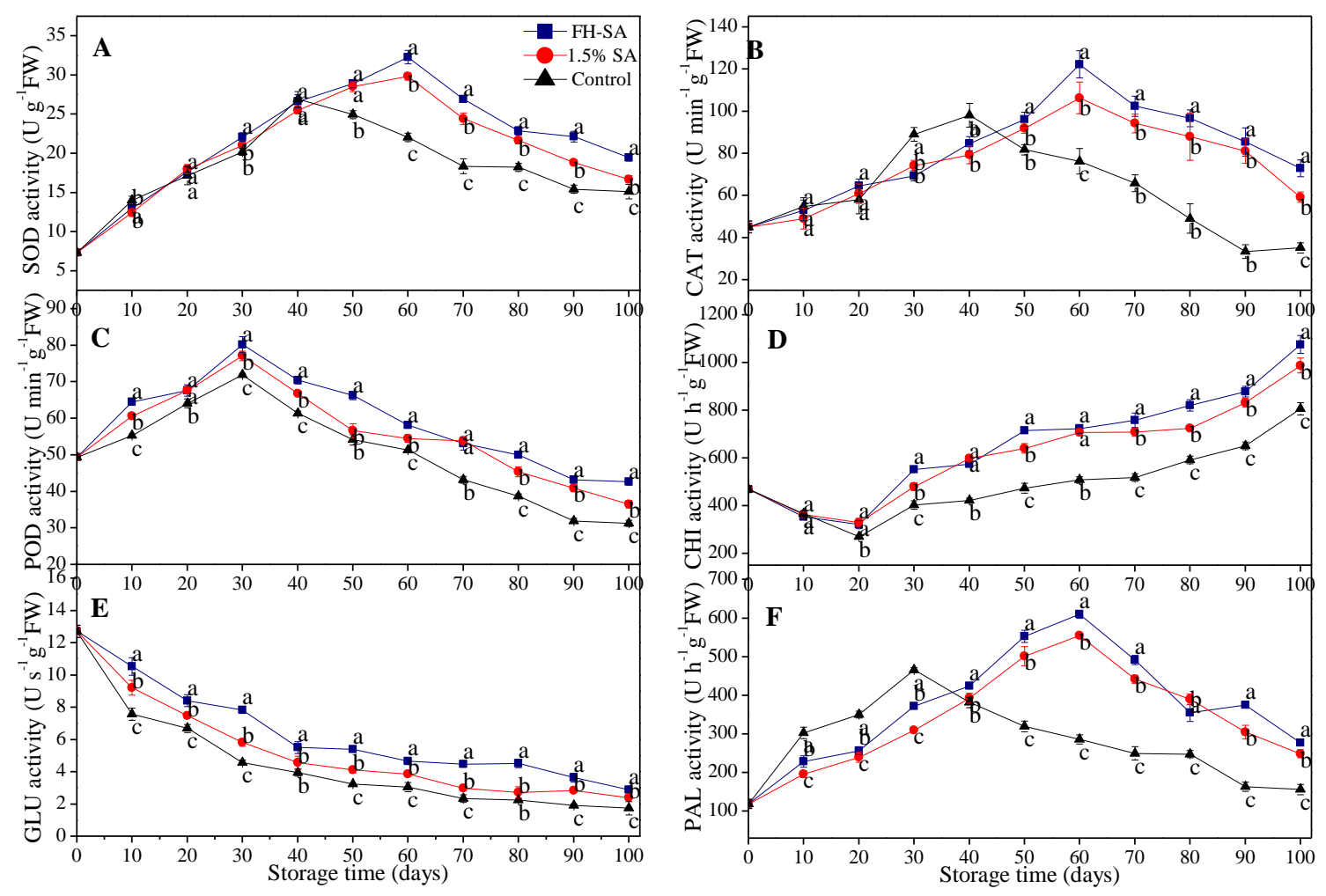

Fig.6. Changes in SOD (A), CAT (B), POD (C), CHI (D), GLU (E) and PAL (F) activities of Nanfeng mandarin stored at $6{ }^{\circ} \mathrm{C}$ for 100 days. Each value represents the mean \pm S.D. of three replicates and means labeled with different lower-case letters are significantly different at $\mathrm{p}<0.05$ according to Duncan's multiple range test. 